Article

\title{
Representing Rape Trauma in Film: Moving beyond the Event
}

\author{
Amanda Spallacci \\ Department of English and Film Studies, University of Alberta, Edmonton, AB T6G 2R3, Canada; \\ spallacc@ualberta.ca
}

Received: 28 September 2018; Accepted: 4 January 2019; Published: 9 January 2019

\begin{abstract}
Trauma theorists foreground the unrepresentability of trauma; however, with modern innovations in visual representation, such as the photograph and cinema, depictions of trauma have begun to circulate across different mediums for a variety of audiences. These images tend to problematically present the traumatic event rather than the effects of trauma, such as traumatic memory. Specifically, some contemporary Hollywood popular films and television series that include rape as their subject matter often include a rape scene that can evoke affects such as disgust or empathy, and while these affects can last the duration of the film, they fail to shift popular discourses about rape because affect is more productive when it focuses on effects instead of events. As trauma studies has shifted to memory studies in the Humanities, and rape has become more prominent in popular culture through the circulation of personal testimony on social media and memoir, depictions of rape in cinema have slowly started to change from presentations of rape scenes to representations of rape trauma that highlight different affects, such as shame. Using Monster (2003), Girl with the Dragon Tattoo (2011), Room (2015), and the television series, 13 Reasons Why (2017) and Sharp Objects (2018) as case studies, this paper argues that, for an audiovisual depiction of rape to shift popular discourses about rape, it would have to function rhetorically to widen the cultural understanding of rape trauma beyond the event, and demonstrate that rape trauma should be understood as part of the personal, unconscious, cultural, and visual mediation of traumatic memory.
\end{abstract}

Keywords: trauma; memory; affect; rape; Hollywood cinema

\section{Introduction}

Current theories of trauma stress the impossibility of its representation (Meek 2009, p. 6) and, as a result, a significant number of contemporary Hollywood popular films and television programs present the traumatic event as opposed to representing trauma itself. This tendency is particularly true of narratives involving rape scenes: rape tends to be represented in film and television through a rape scene that marks the event as trauma rather than traumatic memory. The affects generated from the construction of these scenes produce a short-term effect, as "they make the movie viewing powerful rather than merely an intellectual exercise" (Plantinga 2009, p. 6); yet, in the right context and in the long-term, affects "may burn themselves into memories of audiences and may become templates for thinking and behavior" (p. 6). Similarly, Smith (1995) claims that, in phenomenological and affective terms, "no matter how far our beliefs and values are initially shaped by social structures ... we are capable of expanding and adopting our existing conceptual frameworks through new experience including our experience of fictional representation" (p. 52). Rather than adopt the trauma studies approach that insists on the impossibility of representing trauma-and, as a result opting to focus on the traumatic event-some recent cinematic depictions of rape represent the trauma resulting from the sexual violence through the concept of cultural memory, which "can best be understood at the junction where the individual and social come together" (Hirsch and Smith 2002, p. 7). The cinematic 
choice not to include a rape scene, and instead, to highlight the trauma resulting from the rape, also mirrors the movement in which theories about trauma have begun to shift in academic settings from trauma studies to memory studies alongside discourses about rape that have become increasingly more prominent in popular culture with social media activism such as the \#MeToo movement.

As far back as 2001, Sarah Projansky argued that "rape narratives [in film] help organize, understand, and even arguably produce the social world; they help structure social understandings of complex phenomena such as gender, race, class and nation" (p. 7), even though "film is the least discussed aspect of media culture in relation to rape within scholarly literature" (p. 17). Horeck (2004) analyzes "the link between violence and representation, and fantasy and related reality" (p. 10) as opposed to looking at these entities as distinct or in opposition because representations of rape are foundational to "the terms of the social—and the sexual—contract" (p. 15). Research on rape-revenge films also varies: as Read (2000) claims, these films are indicative of "a historically rather than generically diverse cycle of films" (p. 23), while Heller-Nicholas (2011), through an analysis of rape-revenge films, demonstrates that these films are neither "historically [nor] generically specific" (p. 155). Finally, Henry (2014) situates rape -revenge films as a "cultural key that can help to reveal and interrogate the meanings of rape and the political, ethical and affective responses to it" (p. 3). Regardless of these differences, fiction films that depict a rape scene seem to present a "feminist paradox between a desire to end rape and a need to represent (and therefore perpetuate discursive) rape in order to challenge it" (Projansky 2001, p. 19).

On the topic of representation, Meek (2009) questions "how modern cultural forms, especially those of modern visual media have helped to create conditions in which trauma has assumed such signification" (p. 8). Visual media and discourses about trauma have a symbiotic relationship with each other because "a 'memory' which is represented by media and institutions must be actualized by individuals, by members of a community of remembrance ... on shared notions of the past. Without such actualizations, monuments, rituals, and books are nothing but dead material, failing to have any impact in societies" (Erll 2009, p. 5). As television programs have the advantages or disadvantages of sustaining a longer narrative-and in some cases, commentary—while comprising a different viewing experience than film since they are mostly watched at home and usually broken up into episodes, both television and film are visual mediums that employ the same stylistic approaches. This essay therefore argues that event-based representations of rape-meaning that they focus on the rape rather than trauma-such as is the case in Room (2015); 13 Reasons Why (2017); Monster (2003) and Girl with the Dragon Tattoo ${ }^{1}$ (2011), keep affects contained within the movie or television viewing experience, whereas a television program like Sharp Objects (2018), in representing traumatic memory, can produce a multitude of affects, widen cultural understandings of rape beyond the event, and "shed light on the chronically trauma-producing social structures so as to forge the will to change them" (Kaplan and Wang 2004, p. 12).

\section{Trauma and the Image: From Photography to Film}

Trauma and the image have a long and symbiotic relationship: as Meek (2009) suggests, "to the extent that trauma theory seeks to establish some privileged or exceptional link between testimony, witnessing and traumatic event, it participates in forms of political identification that are often already constituted through media representations" (p. 8). Building on Walter Benjamin's theorization of the photograph, Meek refers to the modern revolution as an era of "rapid social change, technological innovation and the mass availability of information" in which, he argues, with the invention of the photograph and the circulation of images in the public sphere, the photograph "performed important mnemonic functions" (p. 8). As an early form of visual mass media, Sontag (2003) claims that "photographs [became] a means of making 'real' (or 'more real') matters that the privileged and the

1 For the remainder of the paper, Girl with the Dragon Tattoo will be referred to as GWTDT. 
merely safe prefer to ignore" (p. 7). The photograph offered a medium that could not only depict but also authenticate events, and as these images began to circulate publicly, they structured the ways in which the public understood trauma. Furthermore, the photograph's ability to capture an event, then to reproduce and circulate its image, became a means to understanding the effects of trauma on the mind: clinical researchers Elizabeth Brett and Robert Ostroff, as well as Bessel van der Kolk, and literary scholars such as Cathy Caruth, conceptualized the "traumatic image, conceived as an 'iconic' memory that haunts the victim in the form of flashbacks, dreams, and other intrusive repetitions", and this notion of the traumatic image "has come to dominate American discussions of trauma" (Leys 2007, p. 50). The photograph presented an authentic link to the traumatic event and participated in discourses about truth that are still prevalent in trauma studies. For Leys (2000), contemporary discussions of trauma are polarized between mimetic and anti-mimetic models of trauma-two distinctions, Leys argues, that can never be resolved without "falling into contradiction" (305). Nonetheless, by avoiding any mimetic presentations of trauma, such as hypnosis, theorists, such as Cathy Caruth, propose an anti-mimetic model of trauma, arguing that an external event traumatizes a sovereign autonomous subject, establishing "a strict dichotomy between the autonomous subject and the external trauma" (p. 9). For Caruth (1996), memories of a traumatic event do not include a subjective or cultural mediation at the conscious or unconscious level; instead, the flashbacks or nightmares that a survivor experiences after the event are "traces" of the event (p. 4), or as Radstone (2007) calls them "traceless traces" (p. 20). Caruth's theory is important-especially for cases such as rape that take place without a witness or any material evidence-because it tries to authenticate the survivor's testimony by proposing a causal link between symptoms and the event, whereby the symptoms are understood as evidence of the traumatic event. Whether by means of visually depicting a traumatic event, or authenticating a survivor's testimony, both the photograph and trauma theory seek to illuminate trauma that was once below the level of cultural awareness.

Similar to the photograph, some contemporary popular Hollywood film and television programs offer visual depictions of rape through the constructed scene, which expose a criminal act that is frequently silenced and suppressed in contemporary culture. According to Plantinga (2009), "films are ideological because they are rhetorical constructs persuasive in their effects on the audience" (p. 200), and most often the persuasive force of cinema is the affect achieved through certain stylistic techniques that "will influence the spectator's understanding and experience of the film text" (p. 14). Some films and television series that include a rape scene may foreground the protagonist's emotional responses during the rape through close-up shots of the protagonist's face, which may invite empathy from the audience. Alternatively, the rape scene might emphasize the physical occurrence of the assault, usually through close-up shots of the protagonist's body parts while clearly depicting the rapist, which can elicit feelings of disgust from the audience. The film techniques used to construct a rape scene certainly affect viewers strongly; however, this presentation of the rape scene and its subsequent affects also influence the ways in which people conceptualize sexual violence and how they respond to survivors because "affects make ideas and images salient and memorable, they play a role in individual and cultural memory" (p. 5). The prevalence of rape scenes in mainstream Hollywood cinema over representations of rape trauma creates the standard that the burden of proof falls onto the survivor, a standard that does not exist in most real rape cases because, more often than not, the only form of evidence of a rape is the survivor's testimony.

\section{Rape Scenes as Representations of Survivors' Trauma}

Chiefly, two techniques, each producing different affects, are observed in the rape scenes from the films and television program discussed in this section: close-up shots of the protagonist's face which may evoke an empathetic reading from the audience, or close-up shots of the protagonist's body parts along with a close-up of the rapist's face, which can elicit disgust from the audience. One of these techniques is employed in Room, in which Jack, a five-year old born by a woman known as Ma-who was kidnapped and imprisoned at the age of seventeen by Old Nick-hides in a closet while Ma is 
raped by Old Nick. The narrative is presented from Jack's point-of-view, so rather than depict the rape on-screen, the scene consists of a series of extreme close-ups of Jack's face-which appears fearful and confused-as well as diegetic offscreen sounds of a bed squeaking and a man groaning, indicating that Old Nick is raping Ma offscreen. The close-ups could evoke empathy with Jack, who is visibly terrified for his mother, and may also invite the audience to share Jack's concern for his mother.

For its part, 13 Reasons Why is a television series told through a dual narrative by a teenager named Hannah, who committed suicide and left a box of tapes explaining the thirteen reasons why she took her own life, and another teenager named Clay, to whom she left the box. The show oscillates between the past, in which the audience watches the events unfold that Hannah outlines in her voice-over tape recordings, as well as in the present, as Clay negotiates the information he receives from Hannah's tapes. In "Tape 6 Side B", Hannah is left alone in a hot tub with Bryce, who bends Hannah forward, holds her down, and rapes her. This graphic rape scene operates in a circuit of close-up shots of Hannah's face, her hand, and Bryce, coupled with faint non-diegetic music and diegetic on-screen dialogue in which Hannah urges Bryce to stop, while Bryce tells Hannah that she ought to relax, and, finally, the diegetic offscreen sound of Hannah's voice on the tape recording saying, "[t]he way I see it, there are two different kinds of death. If you're lucky you live a long life and one day your body stops working and it's over, but if you aren't lucky you die a little bit over and over." As the diegetic offscreen sound is complete, Hannah stops struggling, as depicted by close-ups of Hannah's listless hand and face while the rape comes to an end.

These two rape scenes are different in the sense that one occurs offscreen while the other is graphic and onscreen; however, the close-up shots of the protagonists' faces foreground the character's emotions, encouraging empathy from the audience in both cases. Once the film has constructed the protagonist as worthy and generated sympathy for the character, Plantinga (2009) argues that a scene is incorporated into the narrative to encourage an empathetic response in the viewer, and that the viewer may "catch some of the emotion the character is thought to be feeling" or from the audience in the theatre (p. 126). Initially, empathy might seem viable, since it implies that spectators can put themselves in the position of the character in this situation, helping them to see that rape is morally condemnable; however, empathy runs the risk of "depoliticizing and universalizing violence" (Dean 2015, p. 7). Thus, rape scenes that invite an empathic reading through a series of close-up shots of the protagonist's face have the potential to collapse differences and render invisible the precarious existence and increased vulnerability that certain people from various subject positions experience in regard to rape.

Additionally, some audiences "tend to make moral judgements on nonmoral grounds, and moral approval of a character might be something like an emotion or an intuition rather than a conscious or deliberate evaluation" (Plantinga 2010, p. 46). For Ahmed (2004), emotions become attached to people, objects, ideas, and events, saturating them with emotional meaning, suggesting that emotions are socially constructed (p. 11). Mainstream media positions white, middle class women as "worthy female victims" (Stillman 2007, p. 491). As a result of these visual and discursive media formations, audiences may feel more inclined to feel empathy once they view "worthy" victims who are raped on-screen. Furthermore, empathy can be a self-interested feeling because it tends to be accompanied by pleasurable feelings such as pride, in which the spectator views themselves as someone who abhors injustice (Plantinga 2010, p. 39). In other words, the representation of a "worthy" victim in close-up shots during a rape scene may invite viewers to feel not only empathy, but also a sense of moral superiority, both of which do not necessarily spark any political engagement after viewing the film or change popular discourses about rape.

Some stylistic film techniques create distance between the protagonist and audience (Plantinga 2010, p. 37), and unlike the close-up of the face that foregrounds the protagonist's emotional response throughout the rape scene, such as in Room and 13 Reasons Why, distanciation techniques, such as numerous close-ups of Aileen's bound wrists and hands in Monster, for example, as well as continuous close-ups of Lisbeth's leg, arm, back, and buttocks in GWTDT, foreground the physical 
violence of rape. The depictions of violence in question are achieved at the expense of completely dehumanizing Aileen and Libseth, and rather than challenge the beliefs held by most men who abuse women - men who fail to see women as human, but as body parts (Russell 1993, p. 135) - these representations perpetuate these oppressive discourses about women. In this respect, Young (2009) coins the term "criminological aesthetics" to explain that "crime images are structured according to a binary logic of representation making one visible and the other invisible" (p. 32), and subjectivities associated with criminality and crime "are made and remade according to the images ascribed to them" (p. 44). While these images may be fictional, therefore, fictional criminal stories "play an important role in fashioning our real world beliefs and responses" (Plantinga 2009, p. 201). Within the limited number of shots that depict Aileen or Lisbeth's faces throughout their respective rape scenes, Aileen's face is covered with blood and is usually turned to the side, pressed against the car seat, and Lisbeth's face is always completely covered by her hair, while the rapists' faces are illuminated and in close-up or medium close-up. The dehumanization of these women is even more troubling given their subject position because the images simply emphasize the hierarchal social systems and binaries that do not challenge but perpetuate assumptions that subjugate these women. Aileen is homeless, a sex worker, and about to meet Selby for their first date when she is violently raped by a man using a crow bar in a scene that represents the fact that sex workers receive more violent abuse during rape, and they are more often "raped with objects" (Russell 1993, p. 116). Lisbeth is a ward of the state without control or access to her finances, works as an investigative hacker, and identifies as bisexual; she is tased, tied up, and anally raped by Nils Bjurman, her state sanctioned guardian. Caputi (2003) argues that within popular culture, a "good girl bad girl dichotomy" exists that forms assumptions about women's cleanliness and dirtiness, and that "bad women, most non-white women, as well as white trash, prostituted women, lesbians-are denounced as already dirty contaminated, criminal, sexual and animalistic" (p. 7). According to Plantinga (2010), "the rhetorical force of narrative depends in part on what it teaches us about characters and kinds of characters about how to respond to various situations and value the world and its contents" (p. 48). The cultural labels and assumptions about certain groups of women make them increasingly more vulnerable to gendered violence, and rather than problematize these beliefs, the film techniques used throughout the rape scene depict these beliefs in a visual form: by fragmenting the body, Aileen and Lisbeth are dehumanized while experiencing extreme violence due to their subject position in society.

Rape revenge films, such as Monster and GWTDT, fall within the justice genre, which includes themes of justice, injustice, revenge, and retribution, and these themes are governed by moral criteria that many people share (Carroll 2010, pp. 11-12). While empathy can be evoked by film techniques such as the close-up of the protagonist's face, it also involves "a benevolent disposition toward [the protagonist]" (p. 16). Aileen and Lisbeth are not depicted as "pro-family, courteous, [or] mostly pro-social", which are traits that Plantinga (2009) argues that a character must possess in order to be "worthy of our pro-attitude", and subsequently the viewers' sympathy (p. 16); yet, audiences could find themselves on Aileen and Lisbeth's side as they attempt to seek revenge on the rapist. According to Young (2009), in the context of the rape revenge genre, "in order for the women's acts of lethal revenge to make "legal" and cinematic sense, the subsequent series of homicides must be at least symbolically against a proceeding cataclysmically serious event of rape" (p. 45), and often, in order to "manipulate a spectator's stance towards characters and a narrative event", Plantinga (2009) rightly argues that, unlike empathy, disgust is a "direct affect" and is often used in "vengeance narratives ... to make dispatch of the criminal act that functions to ritually purify society of the unwanted contaminate" (pp. 212-3). For example, according to Philippa Gates, Lisbeth's rape "offers more shots of Bjurman's face in anticipation and pleasure during the rape", setting up the narrative for Lisbeth to be "justified in-and, more importantly, celebrated for-her acts of violence against the men who hate women" (Gates 2012, p. 209). Monster and GWTDT include a graphic rape scene, which may evoke disgust in certain viewers; yet, even if some viewers may feel something like an allegiance to Aileen and Lisbeth, Plantinga notes that, because viewers are goal-oriented, they may simply want the 
protagonist to complete a task based on the generic expectations of the narrative rather than on a moral approval of the character. Thus, while empathy is generated through the close-up of the protagonist's face, disgust is often independent of the protagonist and influenced by narrative; however, both empathy and disgust tend to avoid the complex social systems to which rape belongs, as well as the effects of trauma beyond the event.

Regardless of whether the rape scene is meant to fulfill a generic narrative expectation of the justice genre, such as in Monster and GWTDT, or if it functions as one of the thirteen traumatic events that led up to Hannah's suicide in 13 Reasons Why, all three present a graphic rape scene that places the viewer in a voyeuristic position: in Monster, with the exception of two point-of-view shots of Aileen looking at her bound hands, the rape is documented through the passenger car window; in GWTDT, the majority of shots are from the video camera, which is propped on a chair at the back of the guardians room, and the rest of the shots are from the side of the bed; and in 13 Reasons Why, every shot is taken from the side of the hot tub. Young (2009) states that "both cinema and the law require and demand corroboration, and both achieve it by linking violence and vision at the expense of the injured woman" (p. 15); therefore, this voyeurism implicates the viewer as a bystander who bears witness to the graphic rape but cannot intervene, and so these films do not function rhetorically to challenge assumptions or misconceptions about women. While graphic depictions of trauma can vicariously traumatize certain viewers (Kaplan and Wang 2004, p. 10), often, the "public fascination with torn and open bodies" (Seltzer 1997, p. 3) and frequent visual exposure to violent images may cause emotional and intellectual disengagement (Meek 2009, p. 4). Additionally, Russell (1993) claims that because of the prevalence of heterosexual pornography-which she categorizes as material created for heterosexual males-that "combines sex ... with the abuse or degradation of females" (p. 3), certain men need to associate violence with pleasure by pairing violent scenes with arousing or gratifying stimuli such as female nudity (p. 129), and, as a result, films that depict women being raped, tortured and killed are increasingly popular in America (p. 261). In particular, the point-of-view shots from the camera in Lisbeth's backpack capture long shots of her entire naked body, and during her struggle, her buttocks are raised in the air in some instances, and the shots from the side of the bed consist of medium close-up shots of the side of her breast. Overtly sexualizing and highlighting the victim or survivor's nudity in a rape scene may titillate certain viewers, and thus, constructing a graphic rape scene in a culture that fetishizes traumatic events-specifically acts of violence against women-perpetuates the discourses that allow these acts to persist.

Survivors hesitate to disclose sexual violence because rape testimony is framed by legal testimony, which is predicated on coherence, linear narrative structure, comprehensive language, and evidence (Andrews 2014; Hesford 1999; Jensen 2014), as well as by rape myths that include blaming tactics and misinformation about rape that our society believes are facts. Truth of the event is central to testimonies about sexual violence, precisely because "the search for absolute truth is still dominant in legal contexts" (Leydesdorff and Adler 2017, p. 7), and rather than acknowledge that the aforementioned effects of trauma and rape culture are responsible for the survivors' inability to form a legal testimony (Alcoff and Gray 1996, p. 271), defense lawyers often use the effects of trauma as evidence to discredit survivor's testimony. Most rapes occur without a witness, and instead, society bears witness to a testimony; however, cinematic depictions of rape tend to focus on the event-as evidenced by the foregrounding of the rape scene-and as the narrative unfolds, the viewer occupies a voyeuristic role in knowing that the rape happened: the viewer knows that the rape occurred not because they believe the survivor's testimony, but because they bore witness to the event, adhering to the imperative of truth of the traumatic event and its relationship to the iconic veracity of the image. If films are ideological, as Plantinga (2009, p. 200) argues, the rape scene does not challenge popular and oppressive discourses about rape; rather, it is complicit with them. For a film about rape to be ideological, it would have to function rhetorically to widen the cultural understanding of rape trauma beyond the event and demonstrate that rape trauma is "an episode in a longer chain of structural mutations in modern systems that have accumulated a record of violence, suffering and misery" (Kaplan and Wang 2004, 
p. 12). This "longer chain of structural mutations" is perhaps represented in more complex ways in television's "longer chain" in terms of episodic narrative structure, and while some programs, such as 13 Reasons Why, do not capitalize on this formal advantage, it nonetheless allows for a more nuanced critical commentary than film can sometimes provide. If they are to inform or change cultural discourses regarding rape, film and television need to evolve away from an event-centered narrative of rape and towards a representation of traumatic memory that might expose the "modern systems that have accumulated a record of violence, suffering and misery."

\section{Sharp Objects and Traumatic Memory}

Unlike 13 Reasons Why (2017), Sharp Objects (2018) takes advantage of its episodic narrative structure to offer a more nuanced commentary on trauma. The program is a murder mystery mini-series about a journalist, Camille Preaker, who returns to her hometown of Wind Gap to report on the disappearance and murder of two young girls. She discovers that her own experiences while growing up in Wind Gap were not unlike those of the two young women, revealing that personal trauma cannot be dissociated from cultural memory in Wind Gap. The narrative within Sharp Objects oscillates between the present and the past through flashbacks that are rarely assigned meaning, and interactions between characters in the present-which at times mirror the events from the past in different contexts-demonstrate the multi-directionality of the story and its ability to not only represent traumatic memory, but also to "make critical use of it to shed light on the chronically trauma-producing social structures so as to forge the will to change them" (Kaplan and Wang 2004, p. 12). The series refuses narrative closure, both in the conclusion as well as the flashbacks.

First, many unanswered questions remain by the end of the series, an unusual narrative choice for a murder mystery series because a characteristic of the genre is that the narrative tends to reveal who committed the murder and how they conducted the act. Instead, Sharp Objects reveals this information near the end of the credits that follow the final episode, an intriguing choice considering that often people stop watching as soon as the credits appear on the screen. Second, flashbacks appear frequently within the narrative and are often short, fragmented, and are not assigned any direct meaning; throughout the series, they are either triggered by specific objects or settings and signaled by a cut in the present followed by a match-on action shot to a scene from the past, or by dialogue, in which during the conversation in the present, Camille is depicted in close-up followed by a cut to a scene from the past. According to Hirsch and Smith (2002), for survivors, acts of traumatic memory "require agents and specific contexts ... they can be involuntary, repetitious, obsessive" (p. 5), and certain cinematic depictions, according to Kaplan (2005), "mimic the structure of trauma in the way the images intrude increasingly into the narrative without being given meaning and refuse us a sort of closure" (131). Camille's alcoholism and the scars from words that she carved on her flesh are revealed throughout the series. Flashbacks portraying Camille from various ages throughout her life begin to appear in the narrative at a higher frequency, seemingly building to a revelation of the traumatic event-the event that caused Camille's alcohol addiction, the scars on her body, and the intrusive flashbacks-because trauma, as it has been presented in photographs and other visual media as well as conceptualized in theories about trauma and discourses in news media, always involves a presentation of the event or a link to the "truth" of the event. Trauma has assumed this signification because "what is understood as history and as memory is produced by historically specific and contestable systems of knowledge and power that produce them" (Radstone and Hodgkin 2005, p. 11); yet, Ball (2000) suggests that perhaps memory, rather than trauma, is one way to talk about the "affective aftermath of oppression without recourse to idealist notions of coherent identity and 'authentic' experience" because memories can "stand in for experiences" (p. 7). Instead of a grand revelation of the traumatic event, in Sharp Objects, the flashbacks that precede the non-witnessed event are just as significant as the event itself because they demonstrate trauma and traumatic memory as part of a larger chain of oppressive forces. 
A particularly pertinent scene from Sharp Objects is from the third episode of the series, called "Ripe", in which Camille and Richard, a detective sent to Wind Gap to investigate the murders, walk through a forest in which the two young girls who were murdered used to play; Camille, having grown up in Wind Gap and spent a lot of time in the same forest, debriefs Richard on the cultural environment that breeds Wind Gap's social landscape. She refers to previous cases of murdered women from Wind Gap, revealing that some of the cases were never thoroughly investigated because of the cultural labels assigned to these women who "didn't conform to the rules of engagement in Wind Gap", and were often referred to as "lesbians or sluts". This moment and a later scene in which Camille's mother chastises her for being "so willful" and "never sweet" because she cut her hair short as a child, demonstrate that discourses about femininity and image have followed her throughout her life. The flashbacks in which Camille is young with short hair represent her naivety as a child with regard to these discourses about femininity and image; however, between her childhood and teenage years, Camille learned the dangers of cultural labels about women: in flashbacks of her adolescence, Camille has become a cheerleader and has grown her hair long, seemingly in an attempt to adhere to culturally circulated images of femininity as well as to warrant the love of her mother following the death of her younger sister, Marion.

Shortly thereafter, Camille and Richard enter a section of the forest referred to as the "End Zone", which, according to Camille, is where "the football team would have their way with that week's lucky cheerleader". Richard asks if the police were ever notified, and after Camille replies that "of course not", Richard states that, "some people would call that rape ... taking advantage of someone too young to make an informed decision ... sounds criminal. Literally". According to Pribram (2011), if gender is discursively and culturally constructed, then "it becomes possible to intervene and influence predominant perceptions of women", (p. 12) and dialogue in television and film, "enables its narratives to represent many gendered issues productively in their deserved complexity" (p. 15). By identifying as rape an event that, according to Camille, most people in Wind Gap would consider to be consensual, Richard, an outsider in Wind Gap, exposes the pervasiveness of the town's cultural discourses. Furthermore, as a detective, Richard's occupation is to uncover the truth, and because he calls this event rape without material evidence, but rather from an account of the events from Camille, he ascribes value and truth to testimony.

This dialogue about informed consent and rape gives meaning to a previous flashback in which Camille, as a child, walks through the forest into a shed that has slices of dead animals hanging from the ceiling and laid out on a table, as well as graphic pornographic images hanging on the walls. The flashback cuts to a scene in the present of Camille masturbating in a motel room, then cuts back to a flashback of a young Camille masturbating in her childhood bedroom, presumably to the images in the shed. Revisiting this sequence in the context of Camille and Richard's discussion about informed consent and rape illuminates the fact that depictions of violent sexuality, such as those in the pornographic images from the shed, saturate various mediums in popular culture, mediating female sexuality and informing sexual practices, so much so that sexual violence against women becomes status quo. With regard to the murder that they are currently investigating, Camille and Richard agree that the fact that the murderer removed the victim's teeth is "equivalent to rape" because "it's about power", and as the conversation ends, Richard begins walking towards the shed-the shed that has already appeared in numerous flashbacks-and Camille has yet another flashback of herself as a teenager in her cheerleading uniform kneeling on the ground, moving insects around with a stick, as a group of teenage boys are crowded around behind her out of focus. This flashback serves as an acknowledgement that Camille was indeed one of the cheerleaders who was raped by the football team.

As Camille follows Richard into the shed, he unintentionally notes that the shed is a "creepy place for two young girls to hang out", and Camille becomes visibly uncomfortable and exits the shed. Evidently, the shed, with its disturbing contents, is a source of trauma and shame for Camille. Evoking Gilles Deleuze, Probyn (2005) argues that "shame is produced out of the clashing of mind and 
body, resulting in new acts of subjectivity consubstantial with the words in which they are expressed" (p. 147). According to Probyn, sexuality is an "area ripe for shame" (p. x), and, coincidently, one of Camille's scars is of the word "ripe", and the episode in which this scene unfolds is also titled "Ripe". The surface of Camille's skin, with the exception of her face and hands, is carved with negative cultural labels, and these "nasty labels" also appear on various objects throughout the series, serving as titles for each episode while also demonstrating that shame is both personal and cultural. Camille's scars not only expose her practices of self-harm, but also her way of working through trauma, and the scars, similar to the flashbacks, evidence the fact that traumatic memory is never exclusively personal: traumatic memory is conscious, unconscious, and cultural, and is a product of events and effects, of memory and culture, of visual media and trauma itself, which is never exclusively personal, but also social, cultural, and political.

Kaplan and Wang (2004) argue that "trauma intensifies the urgency of re-symbolization and reveals the bankruptcy of the prior symbolization ... and may provide opportunities to tap into the driving force that enables new symbolic expression" (p. 14). Personal testimony and political activism about rape have begun to saturate popular culture across a variety of mediums, and these discourses expose issues such as the suspicion and disbelief with which rape testimony is often met in juridical settings and the public sphere. Relatedly, depictions of rape in contemporary Hollywood cinema have slowly shifted from the presentation of a graphic rape scene that, based on its construction, can generate affects such as disgust or sympathy, towards a representation of traumatic memory that accounts for the "inter-intra-subjective processes through which meanings are conferred, negotiated and mediated" (Radstone 2007, p. 18). More scholarship, however, needs to be generated on films that depict rape. For the case of the rape-revenge genre, for instance, the vengeance sequence following the rape could be rationalized as a simple mimetic depiction of trauma because following the rape, the protagonist becomes the perpetrator; often she puts on his clothing after the event, such as in Monster (2003) and Kill Bill vol 1, before inflicting violence on others, and this representation is arguably just as reductive as anti-mimetic presentations of trauma. Additionally, documentary films about rape tend to avoid rape scenes and cinematic representations of memory, and instead foreground a rape survivor who delivers her testimony in extreme close-up, a technique which might produce empathy, sympathy, or more nuanced affects. Nonetheless, the fact that representations of rape have begun to change in mainstream Hollywood cinema is an encouraging prospect because "trauma produces new subjects" (Kaplan 2005, p. 1), and rather than relegate rape survivors to a mystified silence, new representations of trauma support shared suffering and witnessing. Through new representation of rape trauma, survivors can identify with their own memories onscreen and watch these memories reach wide audiences. Hopefully, the rhetorical nature of nuanced representations of rape in cinema can change the oppressive discourses about rape in popular culture.

Funding: This research received no external funding.

Conflicts of Interest: The author declares no conflict of interest.

\section{References}

Ahmed, Sara. 2004. The Cultural Politics of Emotion. New York: Routledge.

Alcoff, Linda, and Laura Gray. 1996. Survivor Discourse: Transgression or Recuperation? In Getting a Life: Everyday Uses of Autobiography. Edited by Sidonie Smith and Julia Watson. Minneapolis: Minnesota University Press, pp. 198-225.

Andrews, Molly. 2014. Beyond Narrative: The Shape of Traumatic Testimony. In We Shall Bear Witness. Edited by Meg Jensen and Margaretta Jolly. Madison: Wisconsin University Press, pp. 32-47.

Ball, Karyn. 2000. Introduction: Trauma and Its Institutional Destinies. Cultural Critique 46: 1-44. [CrossRef]

Caputi, Jane. 2003. 'Take Back What Doesn't Belong to Me': Sexual Violence, Resistance and the 'Transmission of Affect'. Women's Studies International Forum 26: 1-14. [CrossRef] 
Carroll, Noël. 2010. Movies, the Moral Emotions, and Sympathy. In Film and the Emotions. Special Issue of Midwest Studies in Philosophy. Edited by Peter A. French, Howard K. Wittstein and Michelle Saint. Hoboken: Wiley, vol. 34, pp. 1-20.

Caruth, Cathy. 1996. Unclaimed Experience: Trauma, Narrative, and History. Baltimore: John Hopkins University Press.

Dean, Amber. 2015. Remembering Vancouver's Disappeared Women: Settler Colonialism and the Difficulty of Inheritance. Toronto: University of Toronto Press.

Erll, Astrid. 2009. Cultural Memory Studies: An Introduction. In A Companion to Cultural Memory Studies: An International and Interdisciplinary Handbook. Edited by Sara B. Young, Ansgar Nunning and Erll Astrid. Berlin: Walter de Gruyter GmbH \& Co, pp. 1-15.

Gates, Philippa. 2012. 'Hidden in the Snow': Female Violence Against the Men Who Hate Women in the Millennium Adaptations. In Rape in Stieg Larsson's Millennium Trilogy and Beyond: Contemporary Scandinavian and Anglophone Crime Fiction. Edited by Berit Åström, Katarina Gregersdotter and Tanya Horeck. Basingstoke: Palgrave Macmillan, pp. 193-213.

Girl with the Dragon Tattoo. 2011. Directed by David Fincher. Culver: Columbia Pictures/iTunes.

Heller-Nicholas, Alexandra. 2011. Rape Revenge Films: A Critical Study. Jefferson: McFarland \& Company.

Henry, Claire. 2014. Revisionist Rape-Revenge: Redefining a Film Genre. New York: Palgrave Macmillan.

Hesford, Wendy. 1999. Reading Rape Stories: Material Rhetoric and the Trauma of Representation. College English 62: 192-221. [CrossRef]

Hirsch, Marianne, and Valerie Smith. 2002. Feminism and Cultural Memory: An Introduction. Signs 28: 1-19. [CrossRef]

Horeck, Tanya. 2004. Public Rape: Representing Violation in Fiction and Film. New York: Routledge.

Jensen, Meg. 2014. The Fictional is Political: Forms of Appeal in Autobiographical Fiction and Poetry. In We Shall Bear Witness. Edited by Meg Jensen and Margaretta Jolly. Madison: Wisconsin University Press, pp. 141-57.

Kaplan, E. Ann, and Ban Wang. 2004. Introduction: From Traumatic Paralysis to the Force Field of Modernity. In Trauma and Cinema: Cross Cultural Explorations. Edited by E. Ann Kaplan and Ban Wang. Aberdeen: Hong Kong University Press, pp. 1-23.

Kaplan, E. Ann. 2005. 'Why Trauma Now?' Freud and Trauma Studies. In Trauma Culture: The Politics of Terror and Loss in Media and Literature. New Brunswick: Rutgers University Press, pp. 24-41.

Leydesdorff, Selma, and Nanci Adler. 2017. Introduction: On the Evidence Value of Personal Testimony. In Tapestry of Memory: Evidence and Testimony in Life-Story Narratives. Edited by Nanci Adler and Selma Leydesdorff. New York: Routledge, pp. 1-8.

Leys, Ruth. 2007. Image and Trauma. In From Guilt to Shame: Auschwitz and After. Princeton: Princeton University Press.

Leys, Ruth. 2000. Trauma: A Genealogy. Chicago: Chicago University Press.

Meek, Allen. 2009. Trauma and Media: Theories Histories and Images. New York: Routledge.

Monster. 2003. Directed by Patty Jenkins. Studio: Zodiac Productions/iTunes.

Plantinga, Carl. 2010. 'I Followed the Rules and They All Loved You More': Moral Judgement and Attitudes Towards Fictional Characters in Film. In Film and Emotions. Special Issue of Midwest Studies in Philosophy. Edited by Peter A. French, Howard K. Wittstein and Michelle Saint. Hoboken: Wiley, vol. 34, pp. 34-51.

Plantinga, Carl. 2009. Moving Viewers: American Film and the Spectator's Experience. Oakland: California University Press.

Pribram, E. Deidre. 2011. Emotions, Genre, Justice in Film and Television: Detecting Feeling. New York: Routledge.

Probyn, Elspeth. 2005. Blush. Minneapolis: University of Minnesota Press.

Projansky, Sarah. 2001. Watching Rape: Film and Television in Postfeminist Culture. New York: New York University Press.

Radstone, Susannah. 2007. Trauma Theory: Contexts, Politics, Ethics. Paragraph 30: 9-29. [CrossRef]

Radstone, Susanna, and Katharine Hodgkin. 2005. Introduction. In Memory Cultures: Memory, Subjectivity, and Recognition. Edited by Susannah Radstone and Katharine Hodgkin. New York: Routledge, pp. 1-23.

Read, Jacinda. 2000. The New Avengers: Feminism, Femininity, and the Rape-Revenge Cycle. Manchester: Manchester University Press.

Room. 2015. Directed by Lenny Abrahamson. Toronto: Elevation Pictures/iTunes.

Russell, Diana E. H. 1993. Making Violence Sexy. Edited by Diana E. H. Russell. Buckingham: Open University Press. 
Seltzer, Mark. 1997. Wound Culture: Trauma in the Pathological Public Sphere. October 80: 3-26. [CrossRef] Sharp Objects. 2018. Directed by Jean-March Vallée. Created by Marti Nixon. Los Angeles: Blumhouse Productions/iTunes.

Smith, Murray. 1995. Engaging Characters: Fiction, Emotion, and the Cinema. New York: Oxford University Press. Sontag, Susan. 2003. Regarding the Pain of Others. New York: Picador.

Stillman, Sarah. 2007. 'The Missing White Girl Syndrome': Disappeared Women and Media Activism. Gender and Development 15: 491-502. [CrossRef]

Young, Alison. 2009. The Scene of Violence: Cinema, Crime, Affect. New York: Routledge.

13 Reasons Why. 2017. 12, "Tape 6, Side B". Directed by Jessica Yu, Written by Elizabeth Benjamin. aired March 31 2017, on Netflix. Available online: https://www.netflix.com/watch/80117482 (accessed on 28 September 2018).

(C) 2019 by the author. Licensee MDPI, Basel, Switzerland. This article is an open access article distributed under the terms and conditions of the Creative Commons Attribution (CC BY) license (http://creativecommons.org/licenses/by/4.0/). 